\title{
Downregulation of S100A4 Alleviates Cardiac Fibrosis via Wnt/ $\beta$-Catenin Pathway in Mice
}

\author{
LiJun Qian ${ }^{\mathrm{a}} \quad$ Jian Hong ${ }^{\mathrm{a}} \quad$ YanMei Zhang ${ }^{\mathrm{a}, \mathrm{c}} \quad$ MengLin Zhu $^{\mathrm{a}} \quad$ XinChun Wang ${ }^{\mathrm{a}}$ \\ YanJuan Zhang ${ }^{\mathrm{b}} \mathrm{Ming}_{\mathrm{Ch}}^{\mathrm{a}}$ Jing $\mathrm{Yao}^{\mathrm{b}} \quad \mathrm{Di} \mathrm{Xu}^{\mathrm{a}}$ \\ aDepartment of Geriatrics, The First Affiliated Hospital of Nanjing Medical University, Nanjing, \\ bepartment of Cardiology, The First Affiliated Hospital of Nanjing Medical University, Nanjing, \\ 'Department of Cardiology, The Second Affiliated Hospital of Anhui Medical University, Hefei, China
}

\section{Key Words}

S100A4 • Cardiac fibrosis $\cdot$ Myocardial infraction $•$ Wnt/ $\beta$-catenin $•$ Mice

\begin{abstract}
Background/Aims: Cardiac fibrosis is a pathological change leading to cardiac remodeling during the progression of myocardial ischemic diseases, and its therapeutic strategy remains to be explored. S100A4, a calcium-binding protein, participates in fibrotic diseases with an unclear mechanism. This study aimed to investigate the role of S100A4 in cardiac fibrosis. Methods: Cardiac fibroblasts from neonatal C57BL/6 mouse hearts were isolated and cultured. Myocardial infarction was induced by ligating the left anterior descending coronary artery (LAD). The ligation was not performed in the sham group. A volume of $5 \times 10^{5} \mathrm{pfu} / \mathrm{g}$ adenovirus or $5 \mu \mathrm{M} / \mathrm{g}$ ICG-001 was intramyocardially injected into five parts bordering the infarction zone or normal region. We used Western blotting, quantitative RT-PCR, immunofluorescence, immunohistochemistry and Masson's trichrome staining to explore the function of S100A4. Results: We found significant increases of S100A4 level and cardiac fibrosis markers, and $\beta$-catenin signaling activation in vitro and in vivo. In addition, knockdown of S100A4 significantly reduced cardiac fibrosis and $\beta$-catenin levels. Moreover, the expression of S100A4 decreased after ICG-001 inhibited $\beta$-catenin signal pathway. Conclusion: Downregulation of S100A4 alleviates cardiac fibrosis via Wnt/ $\beta$-catenin pathway in mice. S100A4 may be a therapeutic target of cardiac fibrosis.

\section{Introduction}

Myocardial infarction (MI) is a major cause of death worldwide [1]. Despite its preventions wildly used, such as statins and new anticoagulants [2], cardiac remodeling and heart failure still occur after MI $[3,4]$. In addition to inflammatory reaction, oxidative

L.J. Qian and J. Hong contributed equally to this work.

\begin{tabular}{ll}
\hline $\mathrm{Di}$ Xu & Department of Geriatrics, The First Affiliated Hospital of Nanjing Medical University \\
& Nanjing 210029 (China) \\
& Tel. 8613951805973, E-Mail xudi@jsph.org.cn
\end{tabular}

\section{KARGER}




\section{Cellular Physiology Cell Physiol Biochem 2018;46:2551-2560 \begin{tabular}{l|l} 
DOI: 10.1159/000489683 & Ond 2018 The Author(s). Published by S. Karger AG, Basel \\
www.karger.com/cpb
\end{tabular} \\ Qian et al.: Downregulation of S100A4 Alleviates Cardiac Fibrosis}

stress and cardiomyocyte apoptosis manifested in cardiac remodeling [5], cardiac fibrosis is another pathological hallmark [6] that leads to cardiac systolic and diastolic dysfunction [7]. However, therapies for cardiac fibrosis remain unexplored.

S100 calcium-binding A4 (S100A4), also named fibroblast-specific protein 1 (Fsp1), is unregulated in fibrotic diseases of lung [8], liver [9], kidney [10] and heart [11]. As one member of S100 gene family [12], S100A4 is involved in cellular processes, especially in cell differentiation and cell growth [13]. However, the role of S100A4 in cardiac fibrosis remains unknown. Wnt/ $\beta$-catenin signaling pathway is connected with fibroblast activation [14] and tissue repair [15], including $\beta$-Catenin that activates gene transcription [16] and autocrine Wnt ligand production [17]. Stabilized $\beta$-catenin activates target genes, like S100A4, a process which leads to aggressive tumor growth, poor prognosis and serious metastasis [18]. No data are available about the mechanism of S100A4 in the Wnt/ $\beta$-catenin pathway responsible for cardiac fibrosis.

In this experiment, we investigated the expression of S100A4 in hypoxia cardiac fibroblasts and MI murine models, down-regulated S100A4 with adenovirus transfection, and performed ICG-001 treatment to reveal the mechanism of S100A4 in the Wnt/ $\beta$-catenin signaling pathway in vitro and in vivo.

\section{Materials and Methods}

\section{Ethical approval}

The research was approved by the ethical committee (Approval No. IACUC-1703039) and carried out according to relevant regulations of Nanjing Medical University. All animal experiments were performed observing to the guidelines published by National Institutes of Health (No. 85-23, revised 1996).

\section{Cell culture}

Cardiac fibroblasts (CFs) and myocardial cells (MCs) were isolated from neonatal mice (1-3 days old, Nanjing Medical University Laboratory Animal Center). CFs were cultured in DMEM (GIBCO, Inc., USA) containing $10 \%$ fetal calf serum (GIBCO, Inc., USA) and 1\% penicillin and streptomycin mixtures (Biyuntian, Inc., China) at $37{ }^{\circ} \mathrm{C}$ with $5 \% \mathrm{CO}_{2}$. The third passage were randomly divided and used in experiments.

\section{Cell transfection}

S100A4-shRNA (adenovirus to down-regulate S100A4 expression) and Scr-shRNA (adenovirus transfected with scramble siRNA) were synthesized by Shanghai Jikai Gene Technology. After adenovirus transfection in serum free medium for 8 hours, CFs were cultured with complete medium for another 24 hours. Cell growth and GFP expression were observed with a fluorescence microscope and the best multiplicity of infection $\left(2 \times 10^{7} \mathrm{pfu} / \mathrm{ml}\right)$ was chosen.

\section{Cell hypoxia}

CFs were incubated in GENbag Anaer (Biomerieux SA, France) at $37{ }^{\circ} \mathrm{C}$ with a mixture of $5 \% \mathrm{CO}_{2}, 1 \%$ $\mathrm{O}_{2}$ and $94 \% \mathrm{~N}_{2}$ for $6,8,10,16$, and 24 hours respectively.

\section{Surgical preparations}

A total of 48 adult male C57BL/6J mice (20-25g) were randomly and equally divided into four groups: sham+Scr-shRNA, sham+S100A4-shRNA, MI+Scr-shRNA and MI+S100A4-shRNA. They were anesthetized through intraperitoneal injection of $1 \%$ sodium pentobarbital with the dose of $10 \mathrm{mg} / \mathrm{kg}$. In MI group, the left anterior descending coronary artery (LAD) was ligated. In sham group, the ligation was not performed. Then, a volume of $5 \times 10^{5} \mathrm{pfu} / \mathrm{g}\left(2.5 \mu \mathrm{l} / \mathrm{g}, 2 \times 10^{7} \mathrm{pfu} / \mathrm{ml}\right)$ S100A4-shRNA or Scr-shRNA was intramyocardially injected into five parts bordering the infarction or normal region. One week after surgery, the mice were sacrificed for histology study. 


\section{Cellular Physiology Cell Physiol Biochem 2018;46:2551-2560 and Biochemistry Publishe.1159/000489683 $2018 \quad \begin{aligned} & \text { DOI: } 2018 \text { The Author(s). Published by S. Karger AG, Basel } \\ & \text { www.karger.com/cpb }\end{aligned}$ \\ Qian et al.: Downregulation of S100A4 Alleviates Cardiac Fibrosis}

\section{ICG-001 treatment}

CFs without adenovirus transfection were cultured with $10 \mu \mathrm{M}$ ICG-001 (Selleckchem, Houston, TX, USA) and complete medium for 24 hours. A volume of $5 \mu \mathrm{M} / \mathrm{g}(1 \mu \mathrm{l} / \mathrm{g}, 5 \mu \mathrm{M}) \mathrm{ICG}-001$ was intramyocardially injected into five parts bordering the infarction zone or normal region in murine model.

\section{Cell viability}

Cell viability was identified by 3-(4, 5-dimethylthiozol-2-yl)-2, 5-diphenyltetrazolium bromide (MTT). Briefly, CFs were plated in 96-well plates $\left(1 \times 10^{4}\right.$ /well, $\left.80 \mu \mathrm{l}\right)$ for 24 hours in standard conditions. Then, MTT (20 $\mu \mathrm{l} /$ well, Sigma-Aldrich, Inc., USA) was added and incubated for 4 hours at $37^{\circ} \mathrm{C}$ after CFs subjected treatment. DMSO $(100 \mu \mathrm{l} /$ well, Sigma-Aldrich, Inc., USA) was used to dilute crystallization for 15 minutes at $37^{\circ} \mathrm{C}$. After incubation, absorbance was measured at $570 \mathrm{~nm}$.

\section{Western blotting}

The whole cell lysates $(50 \mu \mathrm{g})$ was separated by SDS-PAGE (8\% and 10\% half-half layered) and transferred to PVDF membranes $(0.25 \mu \mathrm{m}$, Millipore, Inc., Massachusetts, USA). Having been blocked in $5 \%$ BSA at room temperature for 1 hour, the membranes were incubated with proper primary antibodies at $4{ }^{\circ} \mathrm{C}$ overnight. Then, secondary antibodies were used to incubate the membranes at $4^{\circ} \mathrm{C}$ for 2 hours. With potent chemiluminescence kit (Liankebio, Inc., China) and super signal west femto trail kit (Thermo, Inc., USA), the expression of target protein was finally detected. Antibodies used in this study are shown in Table 1.

\section{Quantitative RT-PCR (qRT-PCR)}

Total RNA samples from mice were extracted by TRIzol (Life technologies, Inc., USA). Then, total RNA was reverse-transcribed by a PrimeScript ${ }^{\mathrm{TM}}$ RT reagent kit (TaKara Inc., China) for cDNA synthesis. We used a SYBR Premix Ex Taq ${ }^{\text {TM }}$ II kit (TaKara Inc., China) for miRNA detection. Gene specific primers were used to amplify S100A4 (forward: 5'-TCCACAAATACTCAGGCAAAGAG-3'; reverse: 5'-GCAGTCCCTGGTCAGTAG-3') and GAPDH (forward: 5'-GGTAAGGTCGGTGTGAACG-3'; reverse: 5'-CTCGCTCCTGGAAGATGGTG-3'). In PCR, preincubation at $95^{\circ} \mathrm{C}$ for 30 seconds was first performed, followed by 40 cycles of denaturation $\left(95^{\circ} \mathrm{C}\right.$ for 5 seconds) and annealing $\left(60^{\circ} \mathrm{C}\right.$ for 30 seconds), and a final dissociation. A StepOnePlus Real-Time PCR System (Applied Biosystems, CA, USA) was used to perform qRT-PCR.

\section{Immunofluorescence}

CFs were fixed in $4 \%$ paraformaldehyde and then treated with $0.2 \%$ triton $\mathrm{X}-100$ for 15 minutes at room temperature respectively. Then, CFs were blocked in 5\% BSA at room temperature for one hour and incubated with appropriate primary antibodies at $4^{\circ}$ Covernight. Next day, Alexa Fluor 488 nm goat antirabbit $\operatorname{lgG}(\mathrm{H}+\mathrm{L})$ and Alexa Fluor $594 \mathrm{~nm}$ donkey anti-goat $\lg \mathrm{G}(\mathrm{H}+\mathrm{L})$ was added to CFs for one hour. Cell nuclear were stained with DAPI for 10 minutes. We used a software program (Olympus, Japan) and a laser scanning confocal microscope (LSM5, Zeiss, Germany) for image analysis. The cardiac tissues were prepared into $5 \mu \mathrm{m}$ frozen sections and treated with the similar procedures.

\section{Masson's trichrome staining}

The cardiac tissues were respectively fixed in $4 \%$ buffered formaldehyde, embedded in paraffin, and then prepared into 5- $\mu$ m-thick sections. After then, we performed Masson's trichrome staining to investigate the distribution and the extent of the fibrosis.

Table 1. Antibodies

\begin{tabular}{lcc}
\hline Primary antibodies & Vendor & Product number \\
\hline Anti-S100A4 antibody & Cell Signaling Technology, Inc., Cambridge, UK & Catalog\#13018 \\
$\beta$-catenin antibody & Cell Signaling Technology, Inc., Cambridge, UK & Catalog\#8480 \\
phosphor- $\beta$-catenin antibody & Cell Signaling Technology, Inc., Cambridge, UK & Catalog\#5651 \\
Alpha-Actin (Smooth Muscle) antibody & Epitomics, Inc., California, USA & Catalog\#1184-1 \\
Collagen Type Iantibody & Proteintech, Inc., California, USA & Catalog\#14695-1-AP \\
GAPDH antibody & Bioworld technology, Inc., Nanjing, China & Catalog\#AP0063 \\
Anti-S100A4 antibody & Abcam, inc., California, USA & Catalog\#4639(2) \\
Vimentin antibody & Abcam, inc., California, USA & Catalog\#AB20346 \\
Secondary antibodies & Vendor & Product number \\
Peroxidase-conjugated affinipure goat anti-rabbit IgG (H+L) & Jackson ImmunoResearch Laboratories, Inc., PA, USA Catalog\#111-035-003 \\
Alexa Fluor @488-conjugated affinipure goat anti-rabbit lgG (H+L) & Jackson ImmunoResearch Laboratories, Inc., PA, USA Catalog\#111-545-003 \\
Alexa Fluor @594-conjugated affinipure donkey anti-goat lgG (H+L) & Jackson ImmunoResearch Laboratories, Inc., PA, USA & Catalog\#705-585-147 \\
\hline
\end{tabular}




\section{Cellular Physiology Cell Physiol Biochem 2018;46:2551-2560 and Biochemistry Published on/me: May 14, $2018 \quad \begin{aligned} & \text { DOI: 10.1159/000489683 } 2018 \text { The Author(s). Published by S. Karger AG, Basel } \\ & \text { www.karger.com/cpb }\end{aligned}$

Immunohistochemistry

The cardiac tissues were prepared into 5 - $\mu$ m-thick paraffin sections with deparaffinization and antigen retrieval in a steam cooker in 1 mM EDTA (pH 9.0) for 15 minutes. Then, slides were treated with 5\% BSA at room temperature for 1 hour, appropriate primary antibodies at $4{ }^{\circ} \mathrm{C}$ for 12 hours and then universal secondary antibodies at room temperature for 30 minutes. Before mounting, chromogens and haematoxylin were used for counterstain.

Statistical analysis

All experiments were repeated for at least three times. All qualitative data was analyzed with GraphPad Prism software, paired t test, and ANOVA test. $\mathrm{P}<0.05$ was considered statistically significant.

\section{Results}

\section{Evidence of S100A4 in CFS and MCs}

The mRNA and protein expression of S100A4 was detected in CFs and MCs of neonatal mice. We quantified S100A4 mRNA by qRT-PCR (Fig. 1A) and S100A4 protein by Western blotting (Fig. 1B). Then, CFs were stained red, S100A4 protein stained green and nucleus stained blue by immunofluorescence (Fig. 1C). The results demonstrated more S100A4 existed in CFs than in MCs.

\section{S100A4 expression increased after hypoxia}

According to MTT analysis, cell viability increased gradually at the time points of $0,6,8$, 10, 16, and 24 hours after hypoxia (Fig. 2A). We detected the expression of S100A4 mRNA in CFs by qRT-PCR (Fig. 2B), and the expression of S100A4 protein by Western blotting (Fig. 2C). Both expression levels increased went up and peaked at 16 hours after hypoxia. The level of $\alpha$-SMA (fibrosis indicator) expression increased and peaked at the time point of 24 hours after the hypoxia (Fig. 2D), demonstrating that hypoxia promoted CFs differentiation. The results suggested that S100A4 participated in cardiac fibrosis after hypoxia.

\section{Downregulation of S100A4 reduced cardiac fibrosis after hypoxia}

To reveal the role of S100A4 in cardiac fibrosis, S100A4-ShRNA or Scr-shRNA was transduced into CFs. According to the results of qRT-PCR (Fig. 3A) and Western blotting (Fig. 3B), the mRNA and protein expression of S100A4 decreased dramatically in S100A4ShRNA group, which proved the successful downregulation of S100A4 in mice. Compared with Scr-shRNA and Scr-shRNA H group (treated with hypoxia and Scr-shRNA), $\alpha$-SMA (Fig. 3C) levels were reduced in S100A4-shRNA H group (treated with hypoxia and S100A4ShRNA treatment). The results demonstrated that the knockdown of S100A4 inhibited the differentiation of CFs after hypoxia.

Fig. 1. Expression of S100A4 in neonatal mice cardiac fibroblasts and cardiomyocytes. (A) qRT-PCR showed the relative mRNA ratio of S100A4in cardiac fibroblasts (CFs) and myocardial cells (MCs). (B) The expression of S100A4 protein in CFs and MCs was demonstrated by western blot. (C) Immunoflurescent confocal microscopy revealed S100A4 protein expression in CFs and MCs. Scale bars represent $100 \mu \mathrm{m} ;{ }^{*}, \mathrm{p}<$ 0.05 ; **, $\mathrm{p}<0.01$.

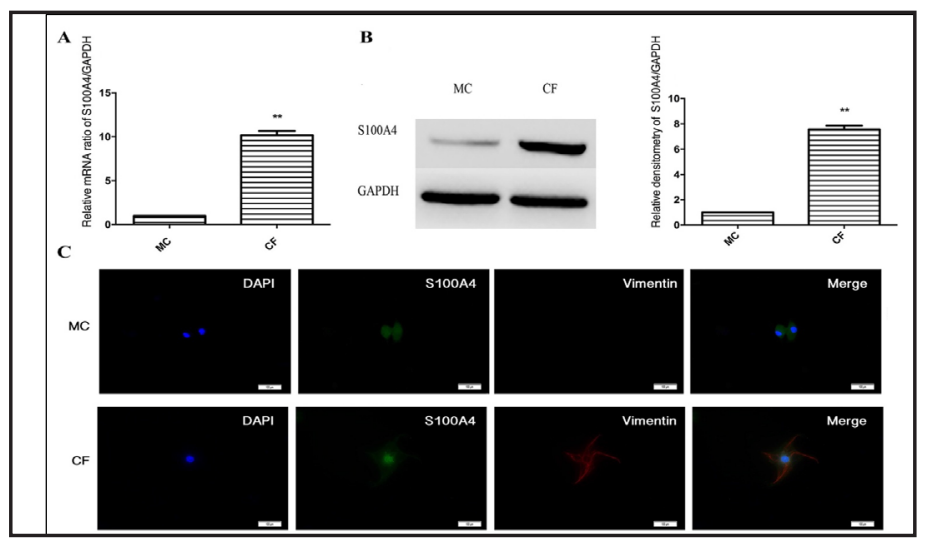


Fig. 2. S100A4 activates myofibroblast differentiation in vitro and in vivo.(A) Cell viability gradually elevated according to MTT analysis, observed at the point of $0,6,8,10$, 16 , and 24 hours after hypoxia. (B) S100A4mRNA expression gradually increased in cardiac fibroblasts by qRT-PCR. (C) Western blot analysis showed S100A4 protein expression gradually raised in cardiac fibroblasts after hypoxia and peaked at 16 hours. (D) Expression of $\alpha$-SMA protein gradually rose after hypoxia and peaked at 24 hours via western blot. (E) Representative Masson's trichrome staining showed the distribution and assessed the extent of the fibrosis, which confirmed the successful construction of MI murine model by comparing the normal, infracted, bordering and remote zones. (F) Immunofluorescence revealed the grown S100A4 expression levels in MI group. (G) Western blot suggested the expression of S100A4 increased significantly in MI murine model. Scale bars represent $100 \mu \mathrm{m}$; ${ }^{*} \mathrm{p}<0.05,{ }^{* *} \mathrm{p}<0.01 ; \mathrm{n}=6$ per group.

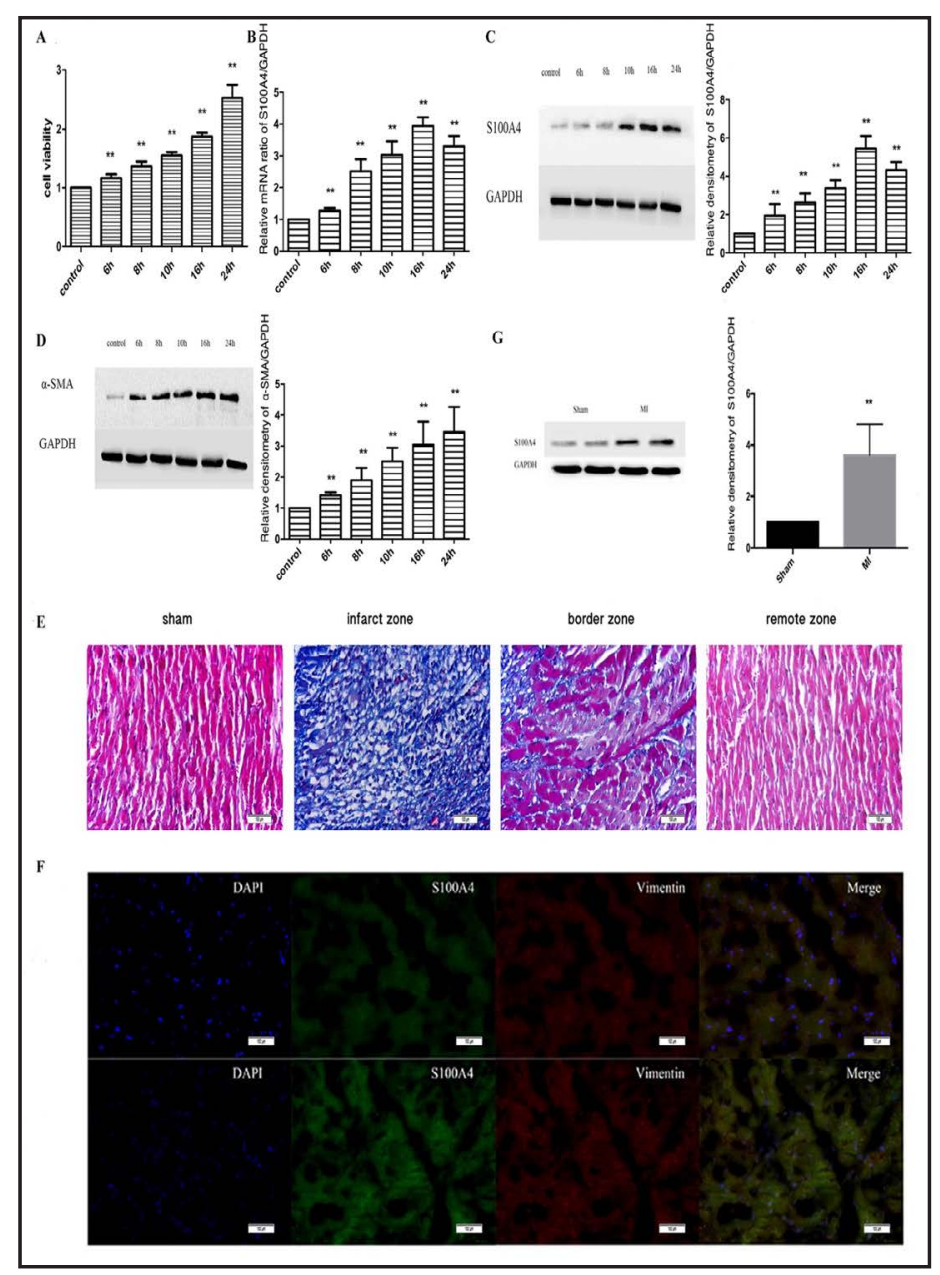

S100A4 expression was elevated after MI

To investigate the function of S100A4 in vivo, murine models were constructed. We investigated the distribution and the extent of the fibrosis by Masson's trichrome staining (Fig. 2E), which confirmed the successful construction of MI murine model by comparing the normal, infracted, bordering and remote zones. The expression of S100A4 increased significantly in MI murine model by immunofluorescence (IF) and Western blotting (Fig. 2F and G).

\section{Knockdown of S100A4 alleviated cardiac fibrosis after MI}

The level of S100A4 expression markedly reduced in S100A4-ShRNA group according to Western blotting and IF (Fig. 3D and F), which confirmed the successful knockdown of S100A4 in murine hearts. The level of $\alpha$-SMA expression obviously dropped (Fig. 3E). According to IF results (Fig. 3G), the area with green stained $\alpha$-SMA in the bordering zone of S100A4-shRNA intramyocardial injection significantly shrunk. The results highlighted that S100A4 downregulation inhibited myofibroblast differentiation in vivo.

\section{$\beta$-catenin expression was up-regulated after hypoxia}

The expression level of $\beta$-catenin increased gradually and peaked at 24 hours after hypoxia (Fig. 4A), which was consistent with the expression trend of S100A4 after hypoxia.

\section{S100A4 mediated cardiac fibrosis via Wnt/ $\beta$-catenin pathway after hypoxia}

The expression of $\beta$-catenin decreased and phosphor- $\beta$-catenin elevated in S100A4ShRNA H group, compared with S100A4-shRNA or Scr-shRNA H group after the transfection 
Fig. 3. Downregulation of S100A4 reduced the indicators of cardiac fibrosis after hypoxia. (A) According to qRT-PCR, S100A4 mRNA dramatically decreased in S100A4-shRNA group as compared with Scr-shRNA group. (B) S100A4 protein expression also significantly reduced in S100A4shRNA group by western blot assay. (C) Expression of $\alpha$-SMA protein reduced in S100A4shRNA $H$ group in comparison with S100A4-shRNA and Scr-shRNA H group by western blot. (D) The expression of S100A4 markedly reduced in S100A4ShRNA group according to western blot in vivo. (E) Expression of $\alpha$-SMA protein was reduced in MI+S100A4-shRNA group by western blot as opposed with MI+Scr-shRNA and sham+S100A4shRNA group.
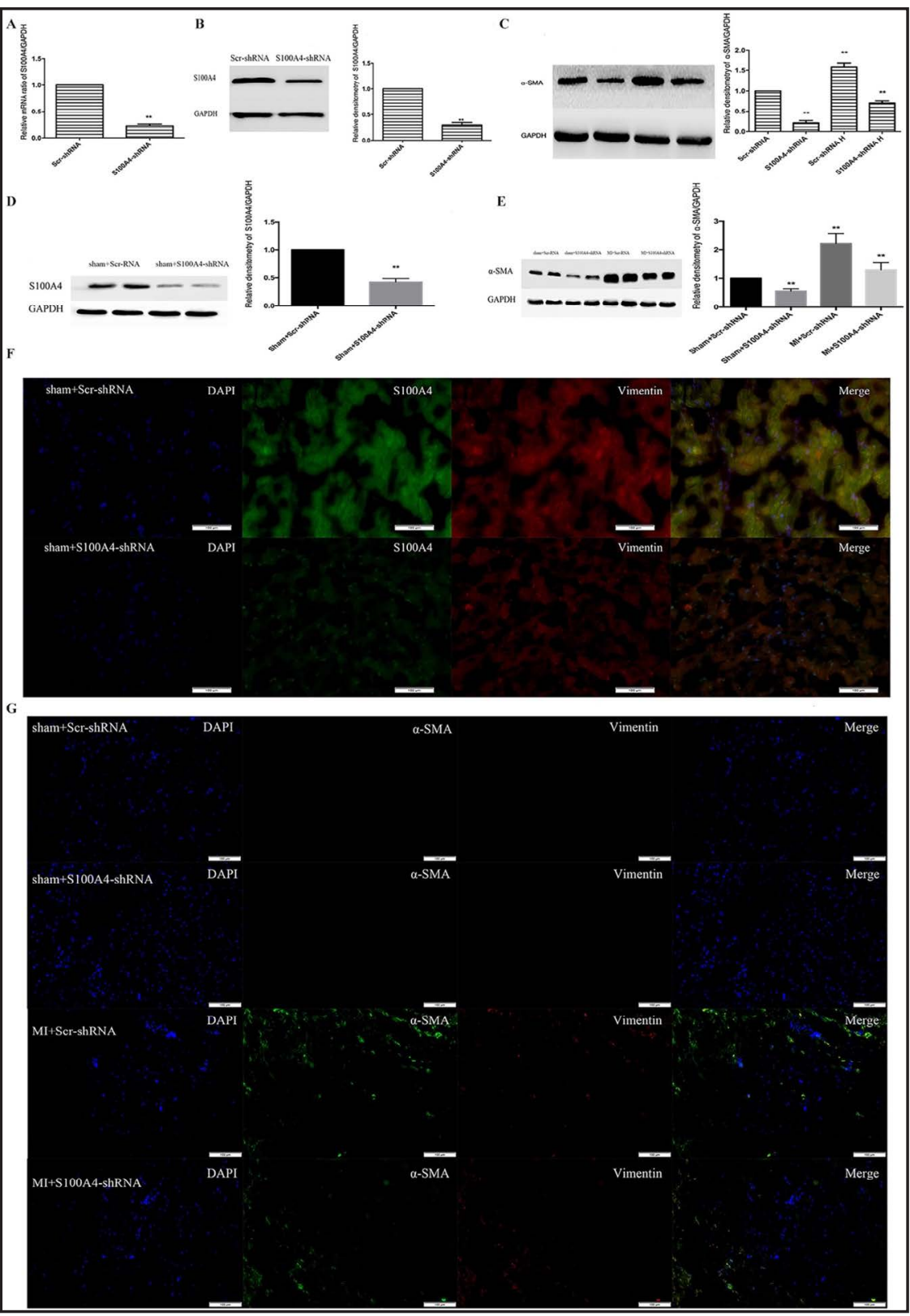

S100A4 expres-

sion levels dramatically decreased in S100A4-ShRNA group by immunofluorescence. (G) Immunofluorescence showed the reduction of $\alpha$-SMA in MI+S100A4-shRNA group. Scale bars represent $100 \mu$ m; ${ }^{*} p<0.05$, $* * \mathrm{p}<0.01 ; \mathrm{n}=6$ per group.

of S100A4-shRNA and a 16-hour exposure to hypoxia (Fig. 4D and E). In addition, S100A4 expression reduced after ICG-001 and hypoxia treatment in vitro (Fig. 4G and H). The results significantly indicated that S100A4 increased cardiac fibrosis via deregulating $\mathrm{Wnt} / \beta$ catenin pathway.

S100A4 activated cardiac fibrosis via Wnt/ $\beta$-catenin pathway after MI

The expression level of $\quad \beta$-catenin increased in MI mice models (Fig. 4B and C), and decreased in S100A4-ShRNA H group compared with S100A4-shRNA or Scr-shRNA H group 
Fig. 4. S100A4activates cardiac fibrosis via Wnt/ $\beta$-catenin pathway in mice(A) Western blot showed the expression of $\beta$-catenin increased gradually at the point of $6,8,10,16$, and 24 hours after hypoxia and peaked at the 24th hour in vitro. (B) Expression of $\beta$-catenin increased in MI murine model by western blot analysis. (C) $\beta$-catenin protein was elevated in MI group by immunofluorescence. (D) Levels of $\beta$-catenin decreased in S100A4-shRNA $\mathrm{H}$ group comparing to S100A4-shRNA group or Scr-shRNA H group by western blot. (E) Western blot suggested the elevated expression of phosphor- $\beta$ catenin in S100A4shRNA $\mathrm{H}$ group. (F) Immunohistochemistry (IHC) showed levels of $\beta$-catenin decreased in S100A4-shRNA $\mathrm{H}$ group. (G) S100A4 mRNA expression reduced in CFs after hypoxia and ICG-001
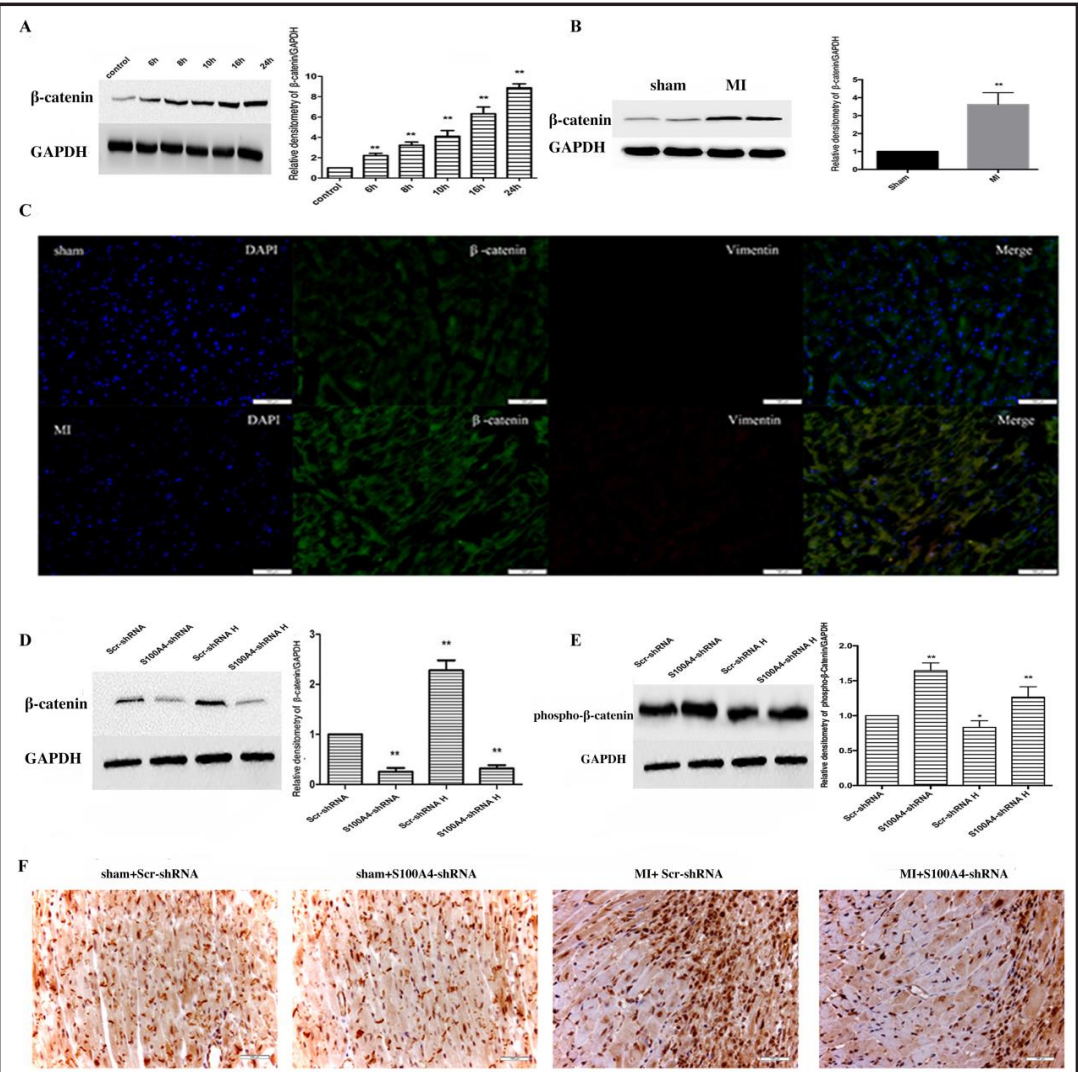
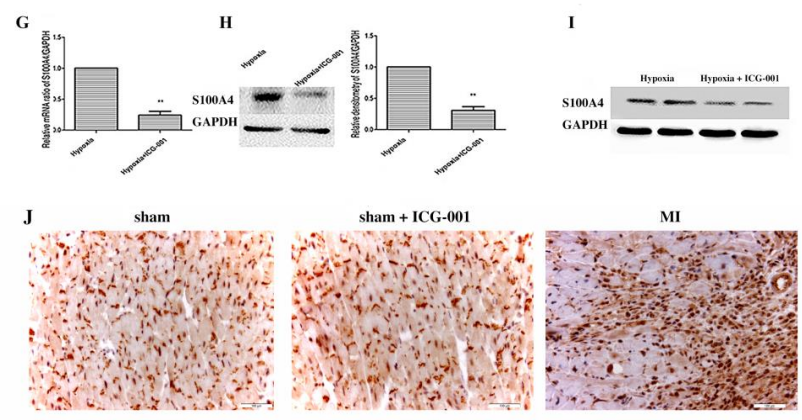

MI
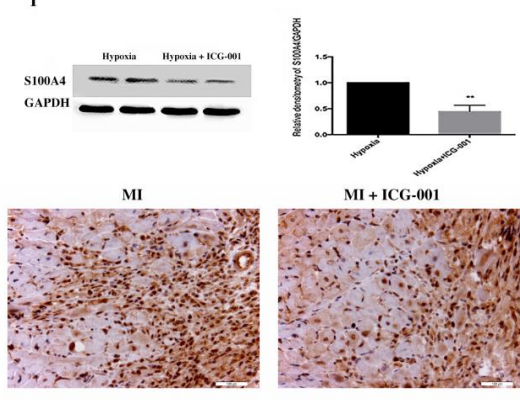
MI + ICG-001

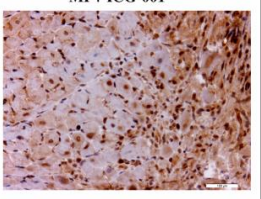
treatment by qRT-PCR.

(H) S100A4 expression also decreased in hypoxia + ICG-001 group by western blot. (I) Western blot showed the reduction of S100A4 protein expression in ICG-001 treated murine group. (J) IHC showed $\beta$-catenin expression decreased in MI+ICG-001 group. Scale bars represent $100 \mu \mathrm{m} ;{ }^{*} \mathrm{p}<0.05,{ }^{* *} \mathrm{p}<0.01 ; \mathrm{n}=6$ per group.

according to immunohistochemistry (Fig. 4F), while the level of S100A4 expression reduced after intramyocardial injection of ICG-001 in vivo (Fig. 4I), which were in accordance with the vitro results. IHC showed the level of $\beta$-catenin expression decreased in MI+ICG-001 group (Fig. 4J), demonstrating the positive effect of ICG-001 in MI.

\section{Discussion}

This experiment researched the role of S100A4 in cardiac fibrosis through Wnt/ $\beta$ catenin signaling. Firstly, we verified S100A4 was mainly expressed in CFs rather than MCs 
Fig. 5. Biocompatibility and safety examination of S100A4-shRNA as a therapeutic agent.(A) S100A4 mRNA in MCs dramatically decreased in S100A4-shRNA group comparing to Scr-shRNA group by qRT-PCR. (B) Western blot showed the reduction of MCs' S100A4 protein expression in S100A4-shRNA group. (C) Flow cytometry suggested no significant difference of MCs apoptosis in S100A4-shRNA and Scr-shRNA group. (D and E) Standard echocardiography detected cardiac morphology and function and showed no concise difference in the $\mathrm{EF}$ and FS values among groups of $0,7,14$ and 28 days after the surgery. (F) MTT analysis showed that cell viability elevated in S100A4-shRNA group comparing to Scr-shRNA or Scr-shRNA H group. $\mathrm{EF}$, ejection fraction; FS, fractional shortening; ${ }^{*} \mathrm{p}<0.05,{ }^{*} \mathrm{p}<0.01 ; \mathrm{n}=6$ per group.

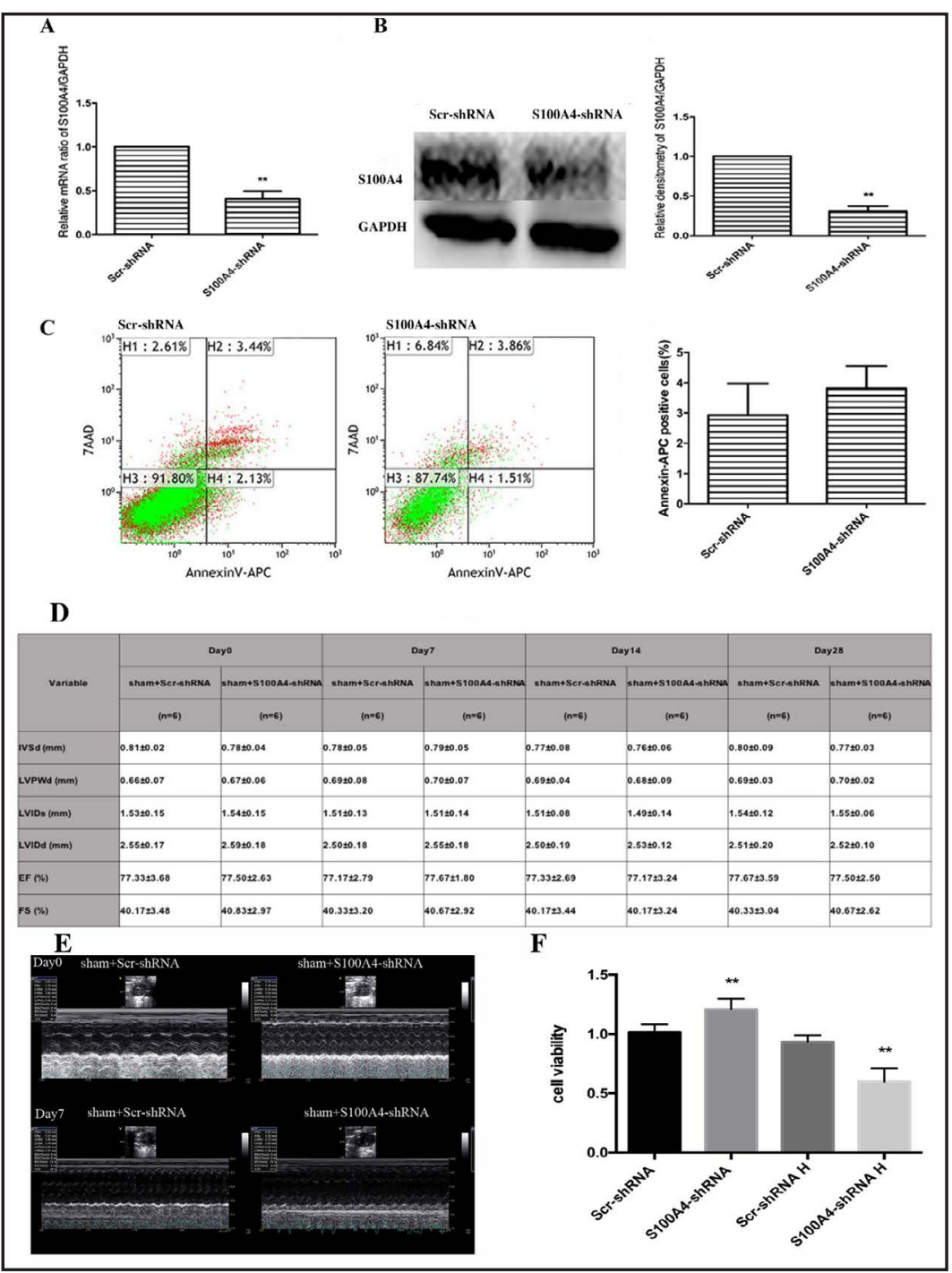

(Fig. 1). Secondly, as hypoxia continued, the expression levels of S100A4, indicators of cardiac fibrosis and $\beta$-catenin all rose dramatically (Fig. 2 and 4). Thirdly, knockdown of S100A4 in vitro and in vivo decreased the expression of $\alpha$-SMA and $\beta$-catenin and increased the expression of phosphor- $\beta$-Catenin (Fig. 3 and 4). Additionally, inhibiting $\beta$-catenin signaling by ICG-001 reduced the expression of S100A4 (Fig. 4), indicating S100A4 may interact with $\beta$-catenin via regulating $\beta$-catenin phosphorylation and deactivation in cardiac fibrosis.

S100A4 is a marker of fibrosis in various cells [7-11] including CFs and MCs [19]. However, few reports have detailed the S100A4 expression in cardiac fibrosis and verified the efficacy and safety of S100A4 downregulation. Here, we carried out additional experiments to examine the biocompatibility and safety of S100A4 in Fig. 5. First, MCs from neonatal mice were used to examine the mRNA and protein expression of S100A4 after adenovirus transfection with qRT-PCR (Fig. 5A) and Western blotting (Fig. 5B). We found the mRNA and protein expression of S100A4 decreased in S100A4-shRNA group compared with ScrshRNA group. Then with flow cytometry, we detected that the apoptosis of MCs after hypoxia showed no significant difference between S100A4-shRNA and Scr-shRNA group (Fig. 5C). Also, standard echocardiography results for cardiac morphology and function showed no

\section{KARGER}


difference between sham+Scr-shRNA and sham+S100A4-shRNA group (Fig. 5D and 5E). The ejection fraction (EF) and fractional shortening (FS) values showed no difference between 0 , 7,14 and 28 day-groups after the surgery. MTT analysis showed cell viability of CFs elevated in S100A4-shRNA group compared to groups of Scr-shRNA or Scr-shRNA H group (Fig. 5F), which validated the biocompatibility of S100A4-shRNA. To summarize, S100A4 knockdown does no harm to heart and is a biocompatible and safe therapeutic agent.

Wnt/ $\beta$-catenin signaling pathway is a hot field in the research on cardiac fibrosis pathogenesis [20]. S100A4 promotes T-cell factor (TCF) to the binding site in Wnt/ $\beta$-catenin signaling pathway of cancer cells $[17,21,22]$. But whether this is true to cardiac fibrosis remains to be proven. Since Wnt/ $\beta$-catenin signaling pathway modulates cytoskeletal dynamics and S100A4 binds heterodimeric $\beta$-catenin/TCF complexes [18], we identified the relationship between S100A4 and Wnt/ $\beta$-catenin signaling pathway. In this experiment, S100A4 increased the expression of extra nuclear $\beta$-catenin protein. Once S100A4 was knocked down, less active $\beta$-catenin and more phosphor- $\beta$-Catenin proteins were quantified, which demonstrating S100A4 expression was regulated by $\beta$-catenin phosphorylation and deactivation. When $\beta$-catenin was lowly expressed, the amount of S100A4 dropped. Our results revealed S100A4 activates Wnt/ $\beta$-catenin signaling pathway in cardiac fibrosis.

\section{Conclusion}

Downregulation of S100A4 alleviates cardiac fibrosis via Wnt/ $\beta$-catenin pathway in mice, which may provide a potential therapeutic target for cardiac fibrosis after MI. More animal experiments, safety assessment and noninvasive myocardial transfection are needed to enhance our findings.

\section{Acknowledgements}

This study was supported by Jiangsu Provincial Key Discipline of Medicine (ZDXKA2016003), by the Priority Academic Program Development of Jiangsu higher Education Institutions (PAPD), by Natural Science Foundation of Jiangsu Province (Grant No. BK20161057) and National Natural Science Foundation of China (Grant No. 81301616, 81601516 and 81271589).

\section{Disclosure Statement}

No conflict of interests exists.

\section{References}

-1 Hullinger TG, Montgomery RL, Seto AG, Dickinson BA, Semus HM, Lynch JM, Dalby CM, Robinson K, Stack C, Latimer PA, Hare JM, Olson EN and van Rooij E: Inhibition of miR-15 Protects Against Cardiac Ischemic Injury. Circ Res 2012;110:71-81.

-2 Qian LJ, Gao Y, Zhang YM, Chu M, Yao J and Xu D: Therapeutic efficacy and safety of PCSK9-monoclonal antibodies on familial hypercholesterolemia and statin-intolerant patients: A meta-analysis of 15 randomized controlled trials. Sci Rep 2017;7:238-248.

- 3 Springeling T, Kirschbaum SW, Rossi A, Baks T, Karamermer Y, Schulz C, Ouhlous M, Duncker DJ, Moelker A, Krestin GP, Serruys PW, de Feyter P and van Geuns RJ: Late cardiac remodeling after primary percutaneous coronary intervention-five-year cardiac magnetic resonance imaging follow-up. Circ J 2013;77:81-88.

4 Hong J, Chu M, Qian L, Wang J, Guo Y and Xu D: Fibrillar Type I Collagen Enhances the Differentiation and Proliferation of Myofibroblasts by Lowering $\alpha 2 \beta 1$ Integrin Expression in Cardiac Fibrosis. Biomed Res Int DOI: $10.1155 / 2017 / 1790808$. 


\section{Cellular Physiology Cell Physiol Biochem 2018;46:2551-2560 \begin{tabular}{l|l} 
DOI: 10.1159/000489683 & and Biochemistry \\
Publisnec onnne:1Vay 14, 2018 & $\begin{array}{l}\text { O 2018 The Author(s). Published by S. Karger AG, Basel } \\
\text { www.karger.com/cpb }\end{array}$
\end{tabular} \\ Qian et al.: Downregulation of S100A4 Alleviates Cardiac Fibrosis}

5 Zhao W, Zhao D, Yan R and Sun Y: Cardiac oxidative stress and remodeling following infarction: role of NADPH oxidase. CardiovascPathol 2009;18:156-166.

6 Liu RM: Oxidative stress, plasminogen activator inhibitor 1, and lung fibrosis. Antioxid Redox Signal 2008;10:303-319.

7 Tao H, Yang JJ, Shi KH, Deng ZY and Li J: DNA methylation in cardiac fibrosis: new advances and perspectives. Toxicology 2014;323:125-129.

-8 Xia H, Gilbertsen A, Herrera J, Racila E, Smith K, Peterson M, Griffin T, Benyumov A, Yang L, Bitterman PB and Henke CA: Calcium-binding protein S100A4 confers mesenchymal progenitor cell fibrogenicity in idiopathic pulmonary fibrosis. J Clin Invest 2017;127:2586-2597.

-9 Taylor S, Herrington S, Prime W, Rudland PS and Barraclough R: S100A4 (p9Ka) protein in colon carcinoma and liver metastases: association with carcinoma cells and T-lymphocytes. Br J Cancer 2002;86:409-416.

10 Le HM, Hegyi I, Cueni LD, Loffing J and Kaissling B: Characterization of renal interstitial fibroblastspecific protein 1/S100A4-positive cells in healthy and inflamed rodent kidneys. Histochem Cell Biol 2005;123:335-346.

11 Schneider M, Kostin S, Strom CC, Aplin M, Lyngbaek S, Theilade J, Grigorian M, Andersen CB, Lukanidin E, Lerche HJ and Sheikh SP: S100A4 is upregulated in injured myocardium and promotes growth and survival of cardiac myocytes. Cardiovasc Res 2007;75:40-50.

12 Donato R, Cannon BR, Sorci G, Riuzzi F, Hsu K, Weber DJ and Geczy CL: Functions of S100 Proteins. CurrMol Med 2013;13:24-57.

13 Diederichs S, Bulk E, Steffen B, Ji P, Tickenbrock L, Lang K, Zanker KS, Metzger R, Schneider PM, Gerke V, Thomas M, Berdel WE, Serve H and Muller TC: S100 family members and trypsinogens are predictors of distant metastasis and survival in early-stage non-small cell lung cancer. Cancer Res 2004;64:5564-5569.

14 Wang X, Zhu Y, Sun C, Wang T, Shen Y, Cai W, Sun J, Chi L, Wang H, Song N, Niu C, Shen J, Cong W, Zhu Z, Xuan Y, Li X and Jin L: Feedback Activation of Basic Fibroblast Growth Factor Signaling via the Wnt/ $\beta$-Catenin Pathway in Skin Fibroblasts. Front Pharmacol 2017;8:32-44.

15 Rudolf A, Schirwis E, Giordani L, Parisi A, Lepper C, Taketo MM and Le GF: $\beta$-Catenin Activation in Muscle Progenitor Cells Regulates Tissue Repair. Cell Rep 2016;15:1277-1290.

16 Gatcliffe TA, Monk BJ, Planutis K and Holcombe RF: Wnt signaling in ovarian tumorigenesis. Int J Gynecol Cancer 2010;18:954-962.

17 van Noort M, Meeldijk J, van der Zee R, Destree 0 and Clevers H: Wnt signaling controls the phosphorylation status of beta-catenin. J BiolChem 2002;277:17901-17905.

18 Stein U, Arlt F, Walther W, Smith J, Waldman T, Harris ED, Mertins SD, Heizmann CW, Allard D, Birchmeier W, Schlag PM and Shoemaker RH: The metastasis-associated gene S100A4 is a novel target of beta-catenin/ T-cell factor signaling in colon cancer. Gastroenterology 2006;131:1486-500.

19 Fujiu K and Nagai R: Fibroblast-mediated pathways in cardiac hypertrophy. J Mol Cell Cardiol 2014;70:6473.

20 Tao H, Yang JJ, Shi KH and Li J: Wnt signaling pathway in cardiac fibrosis: New insights and directions. Metabolism 2016;65:30-40.

21 Zhi X, Tao J, Xie K, Zhu Y, Li Z, Tang J, Wang W, Xu H, Zhang J and Xu Z: MUC4-induced nuclear translocation of $\beta$-catenin: A novel mechanism for growth, metastasis and angiogenesis in pancreatic cancer. Cancer Lett 2014;346:104-113.

22 He L, Lu N, Dai Q, Zhao Y, Zhao L, Wang H, Li Z, You Q and Guo Q: Wogonin induced G1 cell cycle arrest by regulating Wnt/ $\beta$-catenin signaling pathway and inactivating CDK8 in human colorectal cancer carcinoma cells. Toxicology 2013;312:36-42.

23 Fujii H, Li SH, Wu J, Miyagi Y, Yau TM, Rakowski H, Egashira K, Guo J, Weisel RD and Li RK: Repeated and targeted transfer of angiogenic plasmids into the infarcted rat heart via ultrasound targeted microbubble destruction enhances cardiac repair. Eur Heart J 2011;32:2075-2084. 